\title{
PENGEMBANGAN SISTEM DISTRIBUSI AIR BERSIH DI KECAMATAN DAWARBLANDONG, KABUPATEN MOJOKERTO
}

\author{
Riris Sugiarti ${ }^{* 1)}$ dan Alfan Purnomo' \\ ${ }^{1)}$ Departemen Teknik Lingkungan,Institut Teknologi Sepuluh Nopember (ITS), \\ Kompleks Kampus ITS, Sukolilo, Surabaya, 60111 \\ ${ }^{*}$ E-mail: ririssugiarti05@gmail.com
}

\begin{abstract}
Abstrak
Kecamatan Dawarblandong merupakan wilayah pedesaan yang direncanakan akan menjadi kawasan pertambangan mineral dan kawasan strategis sebagai penompang industri besar di Kabupaten Mojokerto. Pengembangan wilayah ini akan mengakibatkan peningkatan ekonomi masyarakat dan peningkatan jumlah penduduk. Meningkatnya jumlah penduduk harus diimbangi dengan pelayanan masyarakat yang lebih baik lagi seperti halnya pemenuhan kebutuhan air bersih. Direncanakannya pengembangan tersebut, maka akan dianalisis kondisi perpipaan. Analisis teknis dilakukan berdasarkan data yang didapatkan di lapangan dan hasil real demand survey. Analisis dan simulasi sistem distribusi dilakukan dengan program EPANET 2.0 dengan mengacu pada SNI 7509-2011. Pengembangan sistem distribusi yang direncanakan untuk tahap 1 mampu melayani $60 \%$ dari jumlah penduduk dengan kebutuhan air bersih rata-rata 56,55 L/dtk yang disediakan oleh PDAM. Tahap 2 melayani 80\% dari jumlah penduduk yang ada dengan kebutuhan air bersih rata-rata dari PDAM sebesar 74,87 L/dtk. Pemenuhan kebutuhan air bersih ini mampu dilayani oleh SPAM Regional Mojo-Lamong. Rencana anggaran biaya dalam perencanaan pengembangan sistem distribusi air bersih sebesar Rp 4.111.117.543,90.
\end{abstract}

Kata kunci: Epanet, Kecamatan Dawarblandong, PDAM, Real demand survey, Sistem distribusi.

\begin{abstract}
The subdistrict Dawarblandong is a rural area planned to become a mineral mining area to support large industries in the regency of Mojokerto. The development of this area would cause community economic improvement and population increase. The increase of population has to be balanced with better community services such as meeting the needs of clean water. Along with the planned development, piping conditions were also analyzed. A technical analysis was done based on data acquired on site and the results of real demand survey. Analysis and simulation of distribution system were done using the program EPANET 2.0 referring to SNI 7509-2011. The development of distribution system is planned in two stages. Stage 1 would be capable of serving $60 \%$ of the population with average clean water need of $56.55 \mathrm{l} / \mathrm{s}$ served by PDAM (public water company). Stage 2 would serve $80 \%$ of the population with average clean water need of $74.87 \% \mathrm{l} / \mathrm{s}$ served by PDAM. This provision of clean water would be adequately served by the regional water distribution system (SPAM) Mojo-Lamong. Budget planned for the clean water distribution system development is $R p$ 4,111,117,543.90.
\end{abstract}

Keywords: Epanet, Dawarblandong subdistrict, PDAM, Real demand survey, Distribution system. 


\section{PENDAHULUAN}

Semua makhluk hidup yang ada di bumi pasti membutuhkan air untuk kelangsungan hidupnya. Tingkat kepentingannya tidak hanya untuk memenuhi kebutuhan air minum saja, namun air bersih juga sangat dibutuhkan dalam kebutuhan sehari-hari seperti halnya untuk mencuci, mandi, membersihkan rumah, pemanas, pendingin udara, dan juga dapat dimanfaatkan sebagai sumber energi (Nazih dan Lawrence, 2016). Penyediaan air yang mencukupi dan terkontrol dalam lingkungan dimana kita tinggal, merupakan hal penting yang harus dipenuhi (Anitaningtyas dan Subchan, 2010). Kebutuhan air akan meningkat seiring dengan semakin meningkatnya jumlah penduduk. PDAM sebagai salah satu badan penyedia air bersih perlu meningkatkan kapasitas produksi dan kualitas air bersih yang diproduksinya (Wahyono $d k k .$, 2007). Pengembangan daerah menjadi salah satu faktor meningkatnya jumlah penduduk yang ada di suatu daerah.

Pengembangan daerah telah diatur dalam rencana tata ruang wilayah pada daerah masing-masing, seperti halnya pengembangan yang terjadi di Kecamatan Dawarblandong. Kecamatan Dawarblandong diperuntukan sebagai kawasan pertambangan mineral dan penompang kawasan industri besar di Kabupaten Mojokerto. Perkembangan kawasan ini dapat meningkatkan perekonomian dan kesejahteraan masyarakat di Kecamatan Dawarblandong, selain itu juga akan meningkatkan jumlah penduduk yang ada di Kecamatan Dawarblandong baik penduduk lokal maupun pendatang sebagai dampak dari pengembangan kawasan industri.

Kecamatan Dawarblandong merupakan salah satu kecamatan yang terletak di Kabupaten
Mojokerto bagian utara dengan tingkat kepadatan penduduk mencapai $877 \mathrm{jiwa} / \mathrm{km}^{2}$ (Badan Pusat Statistik, 2017). Peta administrasi Kecamatan Dawarblandong dapat dilihat pada Gambar 1. Daerah ini merupakan wilayah pedesaaan dengan mata pencaharian utama sebagai petani. Sebagian besar masyarakat masih mengandalkan air sumur sebagai sumber air bersih yang digunakan dengan sumber yang terbatas (USAID, 2014). Sistem distribusi air bersih yang berasal dari PDAM Kabupaten Mojokerto hanya sekitar 1.975 Sambungan Rumah (SR) atau 22\% dari jumlah penduduk di Kecamatan Dawarblandong.

Tingkat pelayanan sistem distribusi air bersih di Kecamatan Dawarblandong mencapai $43,4 \%$ dari jumlah penduduk yang ada. Pelayanan sistem distribusi dilakukan oleh PDAM, PAMSIMAS, dan WSLIC 2. Dalam memenuhi kebutuhannya, sebagian besar sistem distribusi mendapatkan air baku dari sumur pompa dalam. Selain memanfaatkan sumur pompa, pada tahun 2012 pemenuhan kebutuhan air bersih PDAM Kabupaten Mojokerto juga dibantu oleh PDAB dengan memanfaatkan air baku dari Sungai Brantas dengan debit produksi mencapai $50 \mathrm{~L}$ /detik dan akan menambah unit produksi kembali untuk memenuhi kebutuhan air bersih SPAM Regional Mojo-Lamong. Pengembangan sistem distribusi untuk Kecamatan Dawarblandong dan wilayah Kabupaten Mojokerto di sebelah utara Sungai Brantas akan dilayani oleh SPAM Regional MojoLamong dengan debit produksi 200 L/detik. Adanya pengembangan wilayah dan peningkatan jumlah penduduk di Kecamatan Dawarblandong ini perlu adanya suatu pengembangan sistem distribusi air bersih agar kebutuhan air bersih masyarakat dapat terpenuhi. 


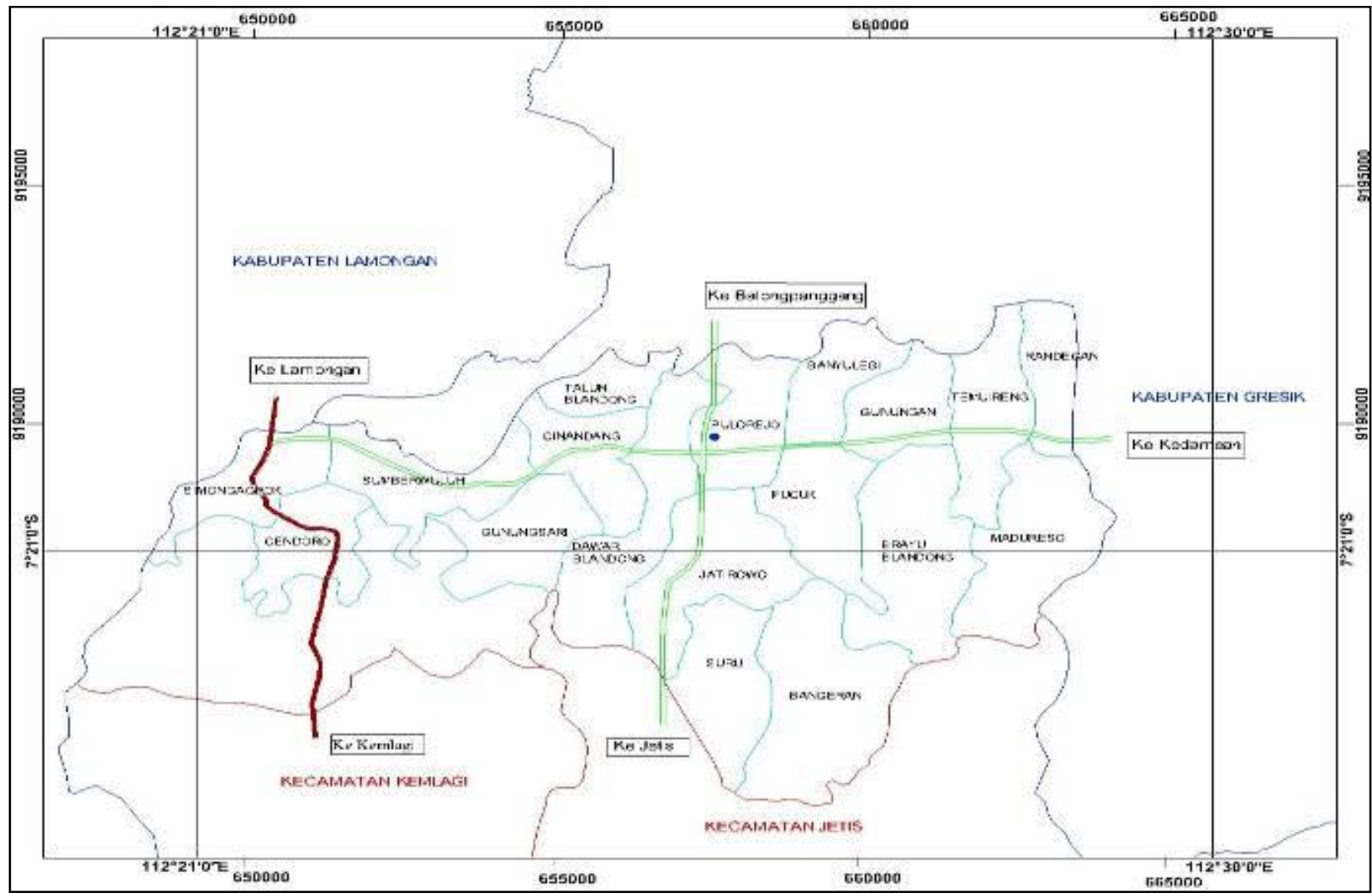

Gambar 1. Peta Administrasi Kecamatan Dawarblandong

\section{METODA}

\section{Pengumpulan Data}

Data-data yang dikumpulkan untuk perencanaan ini meliputi data primer dan data sekunder.

\section{Data Primer}

Data primer adalah data yang diperoleh dari hasil survei secara langsung di lapangan. Data primer yang telah diambil meliputi:

- Data kebutuhan air bersih dan fluktuasi pemakaian air di Kecamatan Dawarblandong.

Data kebutuhan air bersih dan fluktuasi pemakaian air di daerah perencanaan didapatkan dengan melakukan survei secara langsung melalui teknik wawancara pada narasumber. Survei dilakukan dengan metode stratified random sampling. Metode ini digunakan karena dianggap penduduk yang dijadikan objek dibedakan berdasarkan tingkat kepadatan penduduk dan sumber air bersih yang digunakan. Perhitungan jumlah sampel yang digunakan berdasarkan tingkat kepadatan penduduk di masing-masing desa. Jumlah responden dalam perencanaan ini didapatkan dari perhitungan menggunakan persamaan slovin. Berikut ini merupakan perhitungan jumlah responden menggunakan persamaan slovin:

$$
n=\frac{N}{1+\left(N x e^{2}\right)}
$$

Dimana,

$\mathrm{N}=$ jumlah populasi

$\mathrm{e}^{2}=$ batas toleransi kesalahan

Jumlah populasi yang digunakan merupakan jumlah rumah yang ada di Kecamatan Dawarblandong. Terdapat $16.826 \mathrm{KK}$ dengan asumsi 1 rumah terdiri dari $2 \mathrm{KK}$ sehingga didapatkan 8.413 rumah. Batas toleransi kesalahan yang digunakan adalah $8 \%$ dengan nilai kepercayaan sebesar 92\%. Sehingga didapatkan jumlah responden adalah $155 \mathrm{KK}$. 
Desa yang dijadikan objek pengambilan sampel hanya Desa Simongagrok, Madureso, Bangeran, Gunungan, Randegan, Sumberwuluh, Pucuk, dan Talunblandong. Pemilihan desa ini yang mewakili pada kepadatan penduduk tinggi, sedang dan rendah serta mewakili sumber air bersih yang digunakan masyarakatnya yang meliputi PDAM, WSLIC, PAMSIMAS dan mandiri. Pembagian jumlah sampel untuk masingmasing desa berdasarkan jumlah rumah pada masing-masing desa.

Pengambilan sampel dilakukan dengan metode random sampling, dimana setiap rumah memiliki peluang yang sama untuk terambil sebagai responden. Kuesioner survei kebutuhan air bersih terdiri dari beberapa kategori pertanyaan, diantaranya kondisi air baku yang digunakan, pemakaian air, dan rencana penyediaan air domestik. Data mengenai kebutuhan air bersih didapatkan dengan menanyakan volume air yang digunakan setiap hari untuk tiap orang. Sedangkan data fluktuasi air didapatkan dengan menanyakan waktu pemakaian air dan intensitas pemakaian air tiap harinya, misalnya untuk mencuci, mandi, menyiram tanaman, dan lain-lain.

- Data tinggi elevasi rencana titik-titik percabangan jaringan (node untuk program Epanet).

Pengukuran elevasi dilakukan pada titik-titik tertentu dimana titik tersebut merupakan rencana peletakan titik tapping pelanggan atau titik percabangan jaringan (persimpangan jaringan, belokan, dan lain-lain). Pengukuran tinggi elevasi menggunakan Global Positioning System (GPS).

\section{Data Sekunder}

Data sekunder adalah data-data pendukung yang dapat diperoleh dari instansi terkait berupa laporan kegiatan, standar dan peraturan yang berlaku. Data sekunder yang diperlukan pada pelaksanaan perencanaan ini meliputi:

- Peta administrasi Kabupaten Mojokerto

- Peta topografi Kabupaten Mojokerto

- Debit dan peta jaringan pipa utama (pipa transmisi) PDAB Gedeg, Kabupatan Mojokerto

- Data penduduk dan fasilitas umum yang ada di Kecamatan Dawarblandong

- Peta jaringan sistem distribusi PDAM Kab.Mojokerto eksisting

- Data kapasitas pompa PDAM Kab. Mojokerto

- Volume air pelanggan di PDAM Kab. Mojokerto

- RISPAM Kab. Mojokerto

- Daerah layanan WSLIC di Kecamatan Dawarblandong

- Daerah layanan PAMSIMAS di Kecamatan Dawarblandong

- HSPK Kabupaten Mojokerto tahun 2018

Perencanaan sistem distribusi yang dilakukan meliputi aspek teknis dan juga aspek finansial.

- Analisis aspek teknis

Analisis aspek teknis dilakukan perencanaan sistem distribusi air bersih di Kecamatan Dawarbalndong. Analisis aspek teknis meliputi tekanan dalam pipa distribusi, kecepatan aliran dalam pipa, debit dalam pipa, head pompa, karakteristik pipa distribusi disesuaikan dengan standar SNI 7509-2011 tentang tata cara perencanaan teknik jaringan distribusi dan unit pelayanan sistem penyediaan air minum. Simulasi perencanaan jaringan pipa distribusi menggunakan program EPANET 2.0.

- Analisis aspek finansial

Analisis aspek finansial dilakukan dengan menghitung BOQ dan RAB dari pengembangan sistem jaringan pipa distribusi yang telah direncanakan. 


\section{HASIL DAN PEMBAHASAN}

\section{Analisis Kondisi Eksisting}

Sistem distribusi air bersih yang ada di Kecamatan Dawarblandong terbagi menjadi Jaringan Perpipaan (JP) dan Bukan Jaringan Perpipaan (BJP). Pelayanan sistem distribusi jaringan perpipaan dilayani oleh WSLIC, PAMSIMAS dan PDAM. Sedangkan pelayanan air bersih bukan jaringan perpipaan berasal dari sumur galian pompa yang dikelola secara mandiri.

\section{- Layanan PDAM}

PDAM di Kecamatan Dawarblandong mendapatkan sumber air bersih dari sumu pompa dalam (SPD) dan air dari PDAB. Terdapat 2 SPD, yaitu SPD Banyulegi dengan debit 5 L/dtk dan SPD Beru dengan debit 2 L/dtk. Namun untuk saat ini SPD Banyulegi tidak beroperasi. Air yang dialirkan dari PDAB mendapatkan debit 10 L/dtk. Penyaluran menuju daerah layanan, air bersih dari PDAB dipompakan dengan pompa booster dari Reservoir Parengan. Saat ini, daerah layanan PDAM di Kecamatan Dawarblandong lebih fokus pada daerah Dawarblandong bagian timur. Daerah layanan PDAM di Kecamatan Dawarblandong beserta jumlah pelanggan dapat dilihat pada Tabel 1 .
Peta jaringan PDAM eksisting dapat dilihat pada Gambar 2.

Tabel 1. Daerah Layanan PDAM Tahun 2017 di Kecamatan Dawarblandong

\begin{tabular}{|c|l|c|c|}
\hline No. & Nama Desa & $\begin{array}{c}\text { Jumlah } \\
\text { Pelanggan } \\
(\text { SR })\end{array}$ & $\begin{array}{c}\text { Sumber Air } \\
\text { Bersih }\end{array}$ \\
\hline 1 & Dawar & 31 & SPD Beru \\
\hline 2 & pulorejo & 269 & SPD Beru \\
\hline 3 & $\begin{array}{l}\text { Brayu } \\
\text { Blandong }\end{array}$ & 203 & PDAB \\
\hline 4 & Banyulegi & 327 & PDAB \\
\hline 5 & Gunungan & 139 & PDAB \\
\hline 6 & Madureso & 114 & PDAB \\
\hline 7 & Temuireng & 301 & PDAB \\
\hline 8 & Randegan & 165 & PDAB \\
\hline 9 & Pucuk & 383 & PDAB \\
\hline \multicolumn{2}{|c|}{ Total } & 1.932 & \\
\hline
\end{tabular}

- Layanan WSLIC

Program WSLIC merupakan proyek air bersih dan sanitasi untuk masyarakat berpenghasilan rendah. Program ini berada dibawah pengawasan Departemen Kesehatan Republik Indonesia. Pengelolaan program ini diserahkan kepada masyarakat sepenuhnya melalui Lembaga swadaya. Program ini mendapatkan sumber air bersih dari SPD yang selanjutnya dialirkan kepelanggan dengan jaringan pipa yang ada. 


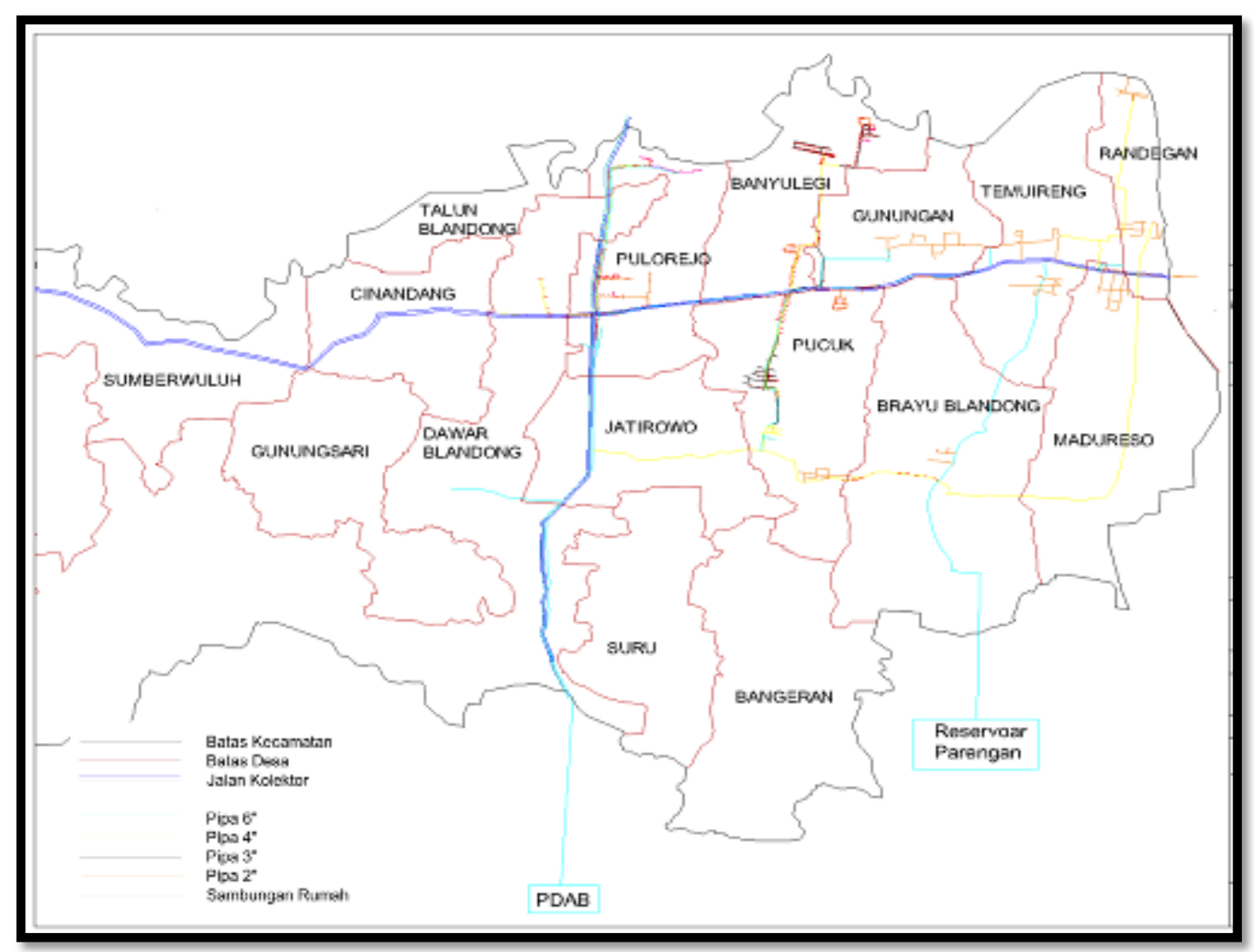

Gambar 2. Peta Jaringan Pipa Eksisting PDAM

Beberapa desa yang menjadi daerah layanan program WSLIC di Kecamatan Dawarblandong, diantaranya di Desa Brayublandong, Gunungsari, Cinandang, Sumberwuluh, Dawarblandong, Jatirowo, Simongagrok, Madureso, Suru dan Cendoro. Perkembangan program ini mampu mencapai tujuan dan berakhir sekitar tahun 2009.

\section{- Layanan PAMSIMAS}

Program ini ditujukan untuk menyediakan akses air minum dan sanitasi masyarakat berpenghasilan rendah di pedesaan maupun peri-urban. Program ini merupakan kelanjutan dari program WSLIC 2, diaman hal yang membedakan adalah daerah layanannya. Program PAMSIMAS di Kecamatan Dawarblandong mulai di bangun sekitar tahun 2015 dengan daerah layanan Desa Madureso, Suru, Brayublandong, Pucuk, Cendoro, jatirowo, Simongagrok, Sumberwuluh, dan Banyulegi. Sumber air baku yang digunakan untuk pemenuhan kebutuhan air bersih menggunakan air sumur dalam, selanjutnya akan dipompakan dan dialirkan melalui pipa ke rumah-rumah pelanggan. Pengelolaan dalam program ini sepenuhnya diserahkan kepada masyarakat melalui Lembaga swadaya yang disebut Tim Kerja Masyarakat (TKM). Anggota dari organisasai ini merupakan masyarakat desa bersangkutan yang dipilih secara demokratis. Lembaga ini bertugas mengelola area layanan, retribusi dan pengelolaan kas. Pada satu desa terdapat satu organisasi yang mengelola. Beberapa desa layanan WSLIC 2 juga merupakan daerah yang dikembangkan oleh PAMSIMAS dengan organisasi pengelola yang sama.

\section{Analisis Kebutuhan Air Bersih}

Analisis kebutuhan air bersih dilakukan untuk mengetahui kebutuhan air bersih masyarakat sebagai acuan untuk perencanaan. Data 
kebutuhan air bersih didapatkan dari hasil survei kebutuhan nyata yang langsung dilakukan pada beberapa masyarakat sebagai responden terpilih. Berdasarkan hasil real demand survey yang telah dilakukan, kebutuhan air masyarakat sangat tergantung dengan harga air yang dikonsumsi. Semakin mahal harga air, maka semakin sedikit air yang akan digunakan. Berikut ini merupakan unit konsumsi air bersih berdasarkan hasil real demand survey.

Tabel 2. Unit Konsumsi Air Bersih

\begin{tabular}{|l|c|}
\hline Sumber Air Bersih & $\begin{array}{c}\text { Kebutuhan } \\
\text { Harian } \\
\text { (L/orang.hari) }\end{array}$ \\
\hline PDAM & 138,7 \\
\hline $\begin{array}{l}\text { WSLIC 2 / } \\
\text { PAMSIMAS }\end{array}$ & 145,6 \\
\hline Air Sumur Pompa & 243,9 \\
\hline Rata-Rata & 176,1 \\
\hline
\end{tabular}

Berdasarkan Tabel 2, dapat dihitung kebutuhan air bersih untuk pengembangan yang akan direncanakan.

- Proyeksi Penduduk

Proyeksi penduduk diperlukan untuk memperkirakan jumlah kebutuhan air yang diperlukan selama tahun perencanaan. Proyeksi penduduk yang dilakukan hanya 10 tahun berdasarkan lama tahun perencanaan, yaitu dari tahun 2018 hingga 2027. Berdasarkan jumlah penduduk yang telah diproyeksikan tersebut, dapat dihitung kuantitas air bersih yang diperlukan untuk memenuhi kebutuhan masyarakat. Metode proyeksi yang akan dipilih adalah metode dengan nilai korelasi paling mendekati 1 . Berdasarkan hasil perhitungan metode yang dipilih adalah metode geometri dengan nilai korelasi yang paling mendekati 1 .

- Proyeksi Fasilitas

Fasilitas yang ada di daerah perencanaan perlu diproyeksikan untuk mengetahui bagaimana perkembangan fasilitas yang diperkirakan akan terjadi di daerah perencanaan. Perkembangan fasilitas dipengaruhi oleh perkembangan jumlah penduduk di daerah perencanaan. Proyeksi fasilitas sangat tergantung dengan proyeksi penduduk yang direncanakan. Berdasarkan proyeksi fasilitas yang dilakukan, selanjutnya didapatkan kebutuhan air non-domestik yang harus dipenuhi. Fasilitas yang akan diproyeksikan merupakan fasilitas umum yang akan digunakan oleh masyarakat dan memerlukan pemenuhan kebutuhan air yang cukup besar dan kontinu seperti halnya fasilitas pendidikan, kesehatan, peribadatan, pasar dan industri.

- Penghitungan Kebutuhan Air Bersih

Kebutuhan air dibedakan menjadi 2 yaitu, kebutuhan air domestik dan kebutuhan air non-domestik. Kebutuhan air domestik merupakan kebutuhan air bersih oleh konsumen domestik atau rumah tangga, sedangkan kebutuhan air bersih non-domestik merupakan kebutuhan air bersih dari konsumen non-domestik atau fasilitasfasilitas umum (Swesty $d k k$., 2012). Berdasarkan hasil perhitungan, kebutuhan air bersih rata-rata untuk tahap 1 sebesar 56,55 L/detik dan untuk tahap 2 kebutuhan air bersih rata-rata sebesar 74,87 L/detik.

\section{Pengembangan Sitem Distribusi}

Perencanaan pengembangan sistem distribusi air bersih di Kecamatan Dawarblandong dibagi dalam 2 tahap perencanaan. Tahap 1 yaitu 5 tahun pertama antara tahun 20182022 dan tahap 2 antara tahun 2023-2027. Menurut data Rispam Kabupaten Mojokerto untuk tahap 1 pengembangan sistem distribusi ditargekan 40\% layanan merupakan Jaringan Pipa (JP) sedangkan $60 \%$ masih berupa Bukan Jaringan Pipa (BJP) yang berupa sumur gali dan sumur gali pompa. JP sendiri merupakan sistem jaringan distribusi perpipaan seperti layanan HIPPAM, PDAM, PAMSIMAS dan WSLIC. Pengembangan tahap 2 ditargetkan $60 \%$ daerah sudah terlayani oleh JP dan harus menurunkan $60 \%$ 
BJP menjadi 40\%. Namun kondisi saat ini pelayanan sistem distribusi air bersih yang ada di Kecamatan Dawarblandong telah mencapai $43,4 \%$ dari jumlah penduduk yang tinggal di wilayah ini, sehingga target pelayanan sedikit bergeser. Pengembangan tahap 1 ditargetkan $60 \%$ dari jumlah penduduk telah terlayani sistem distribusi air bersih dan menurunkan penggunaan BJP dari $56,6 \%$ menjadi $40 \%$. Serta untuk pengembangan tahap 2 direncanakan mampu meningkatkan pelayanan menjadi $80 \%$ dari jumlah penduduk ada dan menurunkan angka penggunaan BJP dari $40 \%$ menjadi $20 \%$.

Pengembangan sistem distribusi yang direncanakan di Kecamatan Dawarblandong sendiri berasal dari PAMSIMAS dan PDAM, sedangkan untuk program WSLIC sudah tidak adanya pengembangan yang dilakukan. Hal ini dikarenakan program ini telah berhenti sejak tahun 2009 dan sebagian besar desa layanan WSLIC 2 akan dikembangkan oleh PAMSIMAS. Pengembangan program PAMSIMAS yang direncanakan mendapatkan sumber air bersih dari Sumur Pompa Dalam (SPD) yang dipasang pada desa target dengan debit tertentu. Pengembangan yang dilakukan oleh PDAM mendapatkan air bersih dari PDAB untuk SPAM Mojo-Lamong yang rencananya akan dipasang 3 pompa dengan head $90 \mathrm{~m}$ untuk masing-masing pompa dengan debit 150 L/dtk. Pompa akan digunakan secara bergantian.

\section{a. Pengembangan Tahap 1 (2018-2022)}

Pengembangan tahap 1 yang direncanakan untuk Kecamatan Dawarblandong oleh PDAM Kabupaten Mojokerto adalah di Desa Dawarblandong, Cinandang dan Talunblandong. Sedangkan pengembangan yang dilakukan PAMSIMAS terletak di Desa Dawarblandong, Pucuk, Suru, Jatirowo, Madureso, Sumberwuluh dan Cendoro. Pada pengembangan tahap 1, PDAM melayani $28,3 \%$ dari jumlah penduduk yang ada, PAMSIMAS melayani $15,6 \%$ dan WSLIC melayani $16,1 \%$ dari jumlah penduduk yang ada. Pengembangan yang signifikan terjadi pada program PAMSIMAS, dimana program ini mampu meningkatkan layanan dari 4,8\% menjadi $15,6 \%$ dari jumlah penduduk yang ada.

b. Pengembangan Tahap 2 (2023 - 2027)

Pengembangan direncanakan program PAMSIMAS direncanakan dengan memaksimalkan debit sumur yang telah terpasang dan melayani daerah tersebut. Daerah pengembangan PDAM direncanakan di Desa Gunungsari, Sumberwuluh dan Simongagrok yang tidak dilayani program PAMSIMAS maupun WSLIC. Hasil pengembangan tahap 2, persen layanan PDAM mencapai $42,7 \%$ dari jumlah penduduk. PAMSIMAS melayani $21,8 \%$ dan WSLIC melayani $15,5 \%$ dari jumlah penduduk.

\section{Analisis Jaringan Dengan EPANET 2.0}

Jaringan sistem distribusi yang telah direncanakan pada pengembangan tahap 1 dan tahap 2 kemudian dianalisis menggunakan program EPANET 2.0. Masing-masing tahap akan dianalisis mengenai diameter pipa yang akan digunakan sehingga jaringan dapat berjalan dengan baik dan sesuai dengan kriteria. Menurut SNI 7509:2011 tentang tata cara perencanaan teknik jaringan distribusi dan unit pelayanan air minum dijelaskan kriteria-kriteria untuk jaringan distribusi air bersih adalah sebagai berikut:

- Besar tekanan air minimum di jaringan pipa distribusi yaitu,

jaringan distribusi utama : $15 \mathrm{~m}$; jaringan distribusi pembagi : $11 \mathrm{~m}$; sambungan pelanggan : 7,5 m.

- Kecepatan maksimum dalam pipa adalah 3 $\mathrm{m} /$ detik dengan kecepatan minimum 0,3 $\mathrm{m} /$ detik.

Berdasarkan kriteria diatas, maka jaringan pipa dianalisis hingga sesuai dengan kriteria. Pengembangan tahap 1 dan 2 memanfaatkan 
pipa jaringan distribusi eksisiting. Beberapa penambahan pipa diperlukan untuk pengembangan tahap 1 dan 2. Hal ini dilakukan untuk mengurangi headloss pada pipa. Headloss yang terlalu besar akan membuat tekanan pada pipa menurun dan tidak memenuhi standar tekanan di titik tapping dan SR. Selain itu, penambahan pipa mampu mengurangi kecepatan pipa agar tidak melebihi $3 \mathrm{~m} / \mathrm{s}$. Kecepatan pipa yang terlalu tinggi dapat mengakibatkan penggerusan pada pipa dan kecepatan yang terlalu rendah yakni kurang dari $0,3 \mathrm{~m} / \mathrm{s}$, akan membuat air susah mengalir.

Pada analisis tahap 1 diperlukan beberapa penambahan pipa secara paralel untuk mempertahankan kecepatan dalam pipa dan mengurangi headloss dalam pipa. Pada Gambar 3, contoh paralel pipa berada di posisi detail A. Gambar detail A dapat dilihat pada Gambar 4.

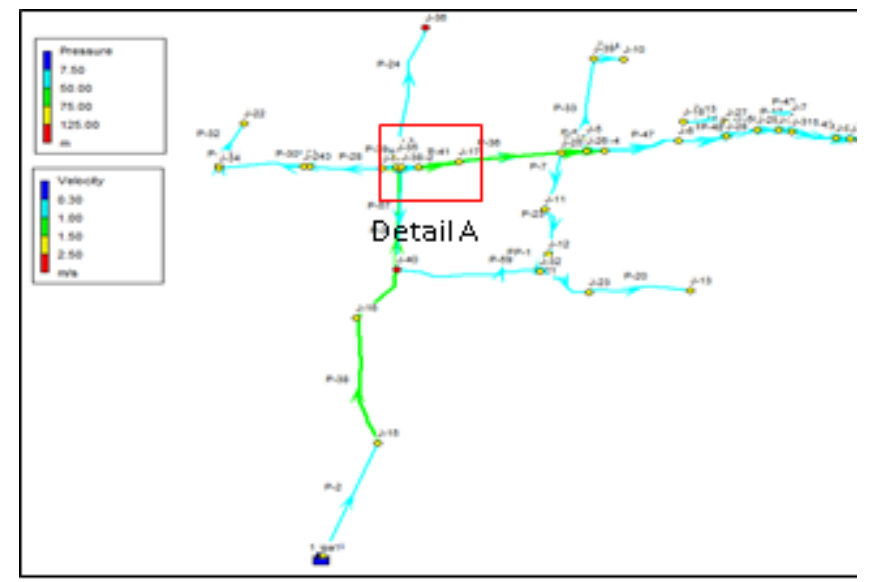

Gambar 3. Jaringan Pipa Tahap 1

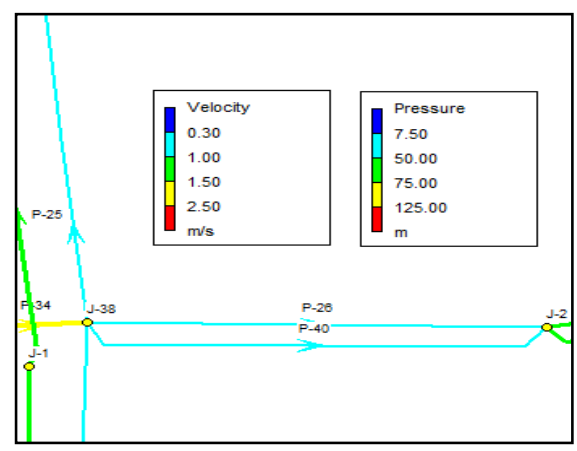

Gambar 4. Detail A
Pengembangan tahap 2 juga dianalisis menggunakan program Epanet 2.0. Hasil analisis program Epanet 2.0 pada tahap 2 dapat dilihat pada Gambar 5.

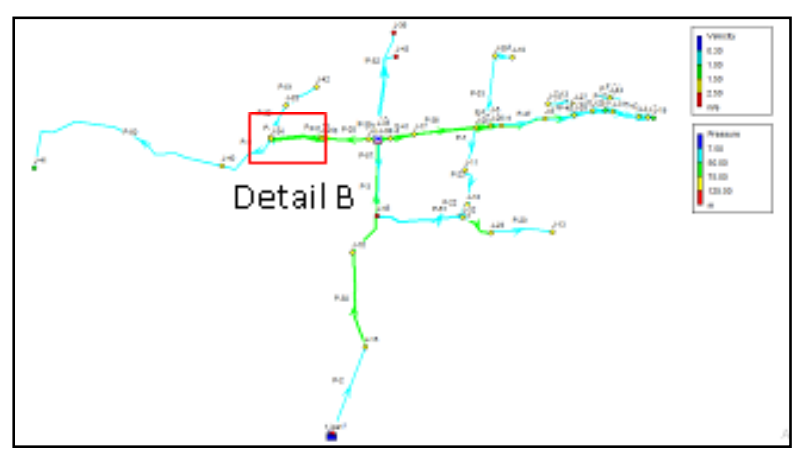

Gambar 5. Jaringan Pipa Tahap 2

Pada pengembangan tahap 2 juga diperlukan penambahan paralel pipa. Posisi paralel pipa detail B dapat dilihat pada Gambar 6.

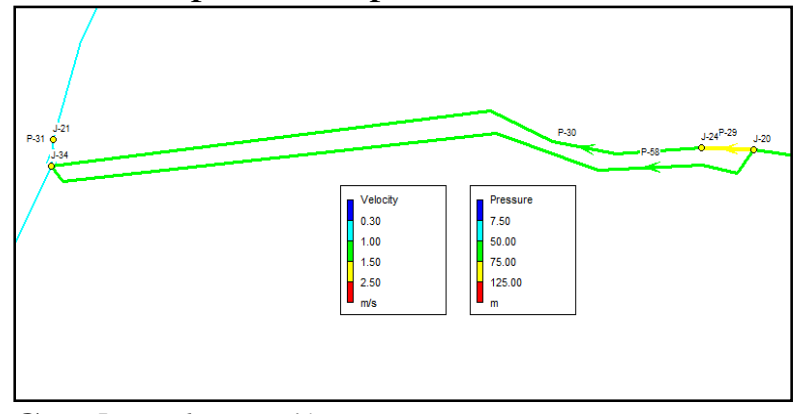

Gambar 6. Detail B

\section{BOQ dan RAB}

BOQ dan RAB yang dihitung mulai dari pengadaan pipa, pengadaan aksesoris pipa, penanaman dan pemasangan pipa, serta pengadaan thrust block. Rincian harga untuk pengembangan ini dapat dilihat pada Tabel 3.

Tabel 3. RAB Pengembangan Sistem Distribusi

\begin{tabular}{|c|l|lr|}
\hline No. & \multicolumn{1}{|c|}{ Rincian } & \multicolumn{2}{c|}{ Biaya } \\
\hline 1 & Pengadaan Pipa & $\mathrm{Rp}$ & $1.562 .170 .680,00$ \\
\hline 2 & $\begin{array}{l}\text { Pengadaan Aksesoris } \\
\text { Pipa }\end{array}$ & $\mathrm{Rp}$ & $142.499 .890,00$ \\
\hline 3 & $\begin{array}{l}\text { Penanaman dan } \\
\text { Pemasangan Pipa }\end{array}$ & $\mathrm{Rp}$ & $2.401 .839 .698,72$ \\
\hline 4 & $\begin{array}{l}\text { Pengadaan Trust } \\
\text { Block }\end{array}$ & $\mathrm{Rp}$ & $4.607 .275,18$ \\
\hline & \multicolumn{1}{|c|}{ Total } & $\mathrm{Rp}$ & $4.111 .117 .543,90$ \\
\hline
\end{tabular}




\section{KESIMPULAN}

Kebutuhan air bersih rata-rata di Kecamatan Dawarblandong beragam dan dipengaruhi jenis sistem distribusi yang melayani. Ratarata kebutuhan air bersih sebesar 176,1 L/orang.hari. Kebutuhan air bersih untuk tahap 1 sebesar 56,55 L/dtk dan untuk tahap 2 sebesar 74,87 L/dtk. Pengembangan terbagi menjadi 2 tahap. Tahap 1 direncanakan melayani $60 \%$ jumlah penduduk dengan sistem perpipaan. Pengembangan tahap 2 direncanakan melayani $80 \%$ dari jumlah penduduk dengan sistem perpipaan. Sumber air untuk pengembangan sistem distribusi dari PDAM disediakan oleh PDAB melalui SPAM Regional Mojo-Lamong dengan kapasitas produksi $200 \mathrm{~L} / \mathrm{dtk}$. BOQ pada perencanaan ini meliputi kegiatan pengadaan pipa, pengadaan aksesoris pipa, penggalian dan penanaman pipa dengan total biaya yang diperlukan untuk perencanaan pengembangan ini sebesar Rp 4.111.117.543,90.

\section{DAFTAR PUSTAKA}

Anitaningtyas, D., dan Subchan. (2010). Optimasi Perencanaan Pelayanan Air Bersih Pada Perusahaan Daerah Air Minum Mojokerto dengan Menggunakan Metode Goal Programming (GP). Jurnal Teknik POMITS. Vol. 3(1).

Badan Pusat Statistik. (2017). Kecamatan Dawarblandong dalam Angka 2017. Mojokerto: BPS

Nazih, K., dan Lawrence, W. (2016). Water Engineering: Hidraulics, Distribution, And Treatment. New Jersey: John Wiley and sons, Inc.

Swesty, A., Ery,S.,dan Very,D. (2012). Studi Perencanaan Sistem Penyediaan Air Bersih DiDesa Serang Kecamatan Panggungrejo Kabupaten Blitar. Jurnal Perencanaan.Vol.1(2).
USAID, (2014). Kajian Kerentanan dan Rencana Adaptasi Penyediaan Air Minum PDAM Kabupaten Mojokerto Laporan Rangkuman. Jakarta: IUWASH.

Wahyono, Y., Yudhastuti, R., dan Keman, S. (2007). Pengaruh Pengolahan dan Pendistribusian Terhadap Kualitas Air Pelanggan PDAM Mojokerto. Jurnal Kesehatan Lingkungan. Vol. 3(2) 